\title{
The primacy of ultrasound in the assessment of muscle architecture: precision, accuracy, reliability of ultrasonography. Physiatrist, radiologist, general internist, and family practitioner's experiences
}

\author{
(DiD Rita Chiaramonte \\ (iD) Marco Bonfiglio ${ }^{2}$ \\ (iD) Emilio G. Castorina ${ }^{3}$ \\ (iD) Salvatore A. M. Antoci ${ }^{4}$
}

\begin{abstract}
1. Department of Physical Medicine and Rehabilitation, University of Catania. 95125 Catania, Italy 2. Department for Health activities and Epidemiologic Observatory, Sicily Region, Italy 3. Department of Radiology, of Fondazione Mediterranea "G.B. Morgagni", 95100 Catania, Italy 4. Department of Medicine of Fondazione Mediterranea "G.B. Morgagni", 95100 Catania, Italy
\end{abstract}

http://dx.doi.org/10.1590/1806-9282.65.2.165

SUMMARY

OBJECTIVE: With high-resolution real-time ultrasonography we investigated the muscle architectural parameters of vastus lateralis in healthy volunteers.

PURPOSES: We determined the reproducibility and validity of ultrasonography and the role of the ultrasonographer in assessing muscle architecture. We proposed the most appropriate clinical parameters for objective measurements and an ultrasound protocol of muscle architecture.

METHODS: We conducted an intraobserver and interobserver study. We investigated 21 healthy male volunteers. The subjects were independently evaluated by four different operators using high-resolution real-time ultrasonography. To assess the reproducibility of ultrasound examinations, four operators repeated measurements using the same ultrasound device. Muscle thickness, muscle volume, muscle fiber pennation angle, and subcutaneous adiposity of the vastus lateralis muscle were measured.

RESULTS: Intra-observer (ICC 0.92-0.97), interobserver (ICC 0.78-0.92) reproducibility was good to excellent for all measurements.

CONCLUSION: Simple, reproducible, non-invasive ultrasound measurements of muscle structure easily demonstrated differences in muscle morphology. With a protocol and with objective and repeatable measurements, sonographers from different backgrounds could obtain an objective measurement of ultrasound images with little differences and low variability in results, thanks to the upgrading of diagnostic ultrasound imaging and their clinical skills.

KEYWORDS: Ultrasonography. Quadriceps muscle. Muscle fibers, skeletal.

\section{INTRODUCTION}

With high-resolution real-time ultrasonography (US) we investigated the muscle architectural parameters of vastus lateralis (VL) in healthy volunteers. US

permits to evaluate echo intensity (ECHO), ultrasound imaging of muscle perfusion, transverse and longitudinal sections of the muscle and its thickness at rest 
and during maximal voluntary contractions (MVC), overlying subcutaneous fat, cross-sectional area (CSA), and angled fibers of pennate muscles. Physicians with different specialties could use ultrasound for various applications. Therefore, physiatrist must be able to interpret ultrasound imaging performed by other specialists.

The internal fibers of the vastus muscles are not arranged in any particular manner. They are characterized by the presence of connective-tissue septa. The fascia that surrounds each of the vastus muscles is visualized as a thin hyperechoic layer. Their presence allows distinguishing the vastus intermedius from the VL and rectus femoris. Distinguishing the VL from the VI can be difficult because these two muscles merge laterally ${ }^{1}$. However, US overcomes this difficulty.

The purpose of this study was to examine the reliability and validity of US measures of the architecture of the VL and interrelationships among the architectural parameters. The validity of measurements was investigated by comparing values obtained after three ultrasound measurements from the same operator and other measurements obtained from 4 different specialists: a physiatrist, a radiologist, a general internist, and a family practitioner.

We designed a protocol to detect the most repeatable and objective ultrasound parameters: muscle thickness at rest (MT), CSA, muscle fiber pennation angle $(\theta p)$ and subcutaneous fat thickness (FT) of pennate muscles. A common language facilitated the interpretation of the ultrasound measurements, even if performed by other specialists. Our ultrasound protocol allowed for a complete evaluation and more effective follow-up.

\section{METHODS}

All procedures performed in our study involving human participants followed the ethical standards of the institutional and national research committee, the 1964 Helsinki declaration and its later amendments, or comparable ethical standards. Informed consent was obtained from the participants included in the study.

We conducted an intraobserver and interobserver study. We investigated 21 healthy male volunteers (mean age 32 years, range 26 to 38 years, height $170.2 \pm 5.5 \mathrm{~cm}$, mass $68 \pm 5 \mathrm{~kg}$ ), at rest.

The inclusion criteria were as follows: healthy subjects, without previous lesions of the lower limbs, neither fractures, luxations, distortions, nor injuries to the bones, joints, tendons, and muscles. Exclusion criteria were as follows: immobilization, lesions or trauma or musculoskeletal deformities of the lower limbs, peripheral neuropathy, major medical conditions, and anatomical variations of the lower limb muscles.

The subjects were independently evaluated by four different operators using high-resolution real-time ultrasonography (Acuson S3000 Ultrasound System). After using a warm gel, we performed the ultrasound. Time taken for examinations was recorded (each visit lasted approximately 10-15 minutes). To assess the reproducibility of ultrasound examinations, four operators repeated measurements of the same image of the muscle three times, using the same ultrasound device. For each subject, we applied the same machine setting (gain, focal depth, transducer aperture size, beam steering, depth) in order to reproduce the same technical errors and obtain comparable data.

The subjects were examined in the prone position with hip and knee in neutral position. We examined the VL of the dominant leg, which was scanned axially and then longitudinally. The landmarks, defining the sites of measurement of the $\mathrm{VL}$, were the femur, particularly the greater trochanter, and the kneecap. We measured the MT at rest (Fig. 1), CSA (Fig. 2), $\theta p$ (Fig. 3) and subcutaneous adiposity (Fig. 4). The MT was the vertical distance between the superficial and deep aponeurosis of the VL (muscle belly), measured at the thickest part of the muscle. The CSA was the perimeter of the $\mathrm{VL}$, with a manual tracing of the muscle borders using digital software of our ultrasound system. Pennation angle of the VL was the angle between the muscle fibers and the deep aponeurosis besides the vastus intermedius. We used a 6-18 MHz linear ultrasound probe. When it was possible, we took perforating vessels arising from the muscle, as landmarks.

The Statistical Package for Social Sciences (SPSS, Version 18.0 for Windows; SPSS Inc., Chicago, IL) was used for data analysis. Data were obtained using intra- and interobserver correlation (ICC).

\section{RESULTS}

Results were analyzed using intra- and interobserver correlation (ICC) of values obtained after three 


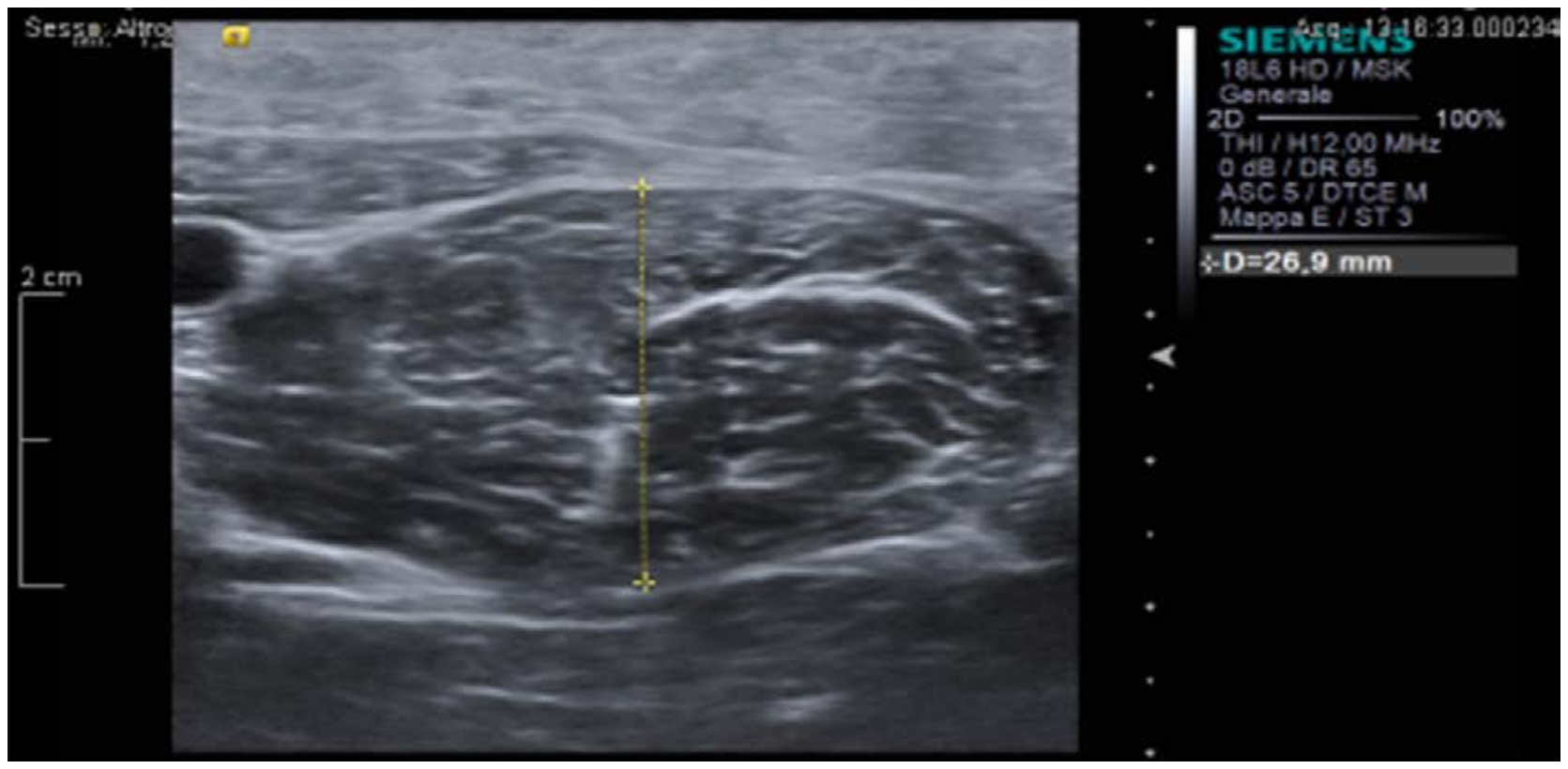

FIGURE 1: MUSCLE THICKNESS AT REST

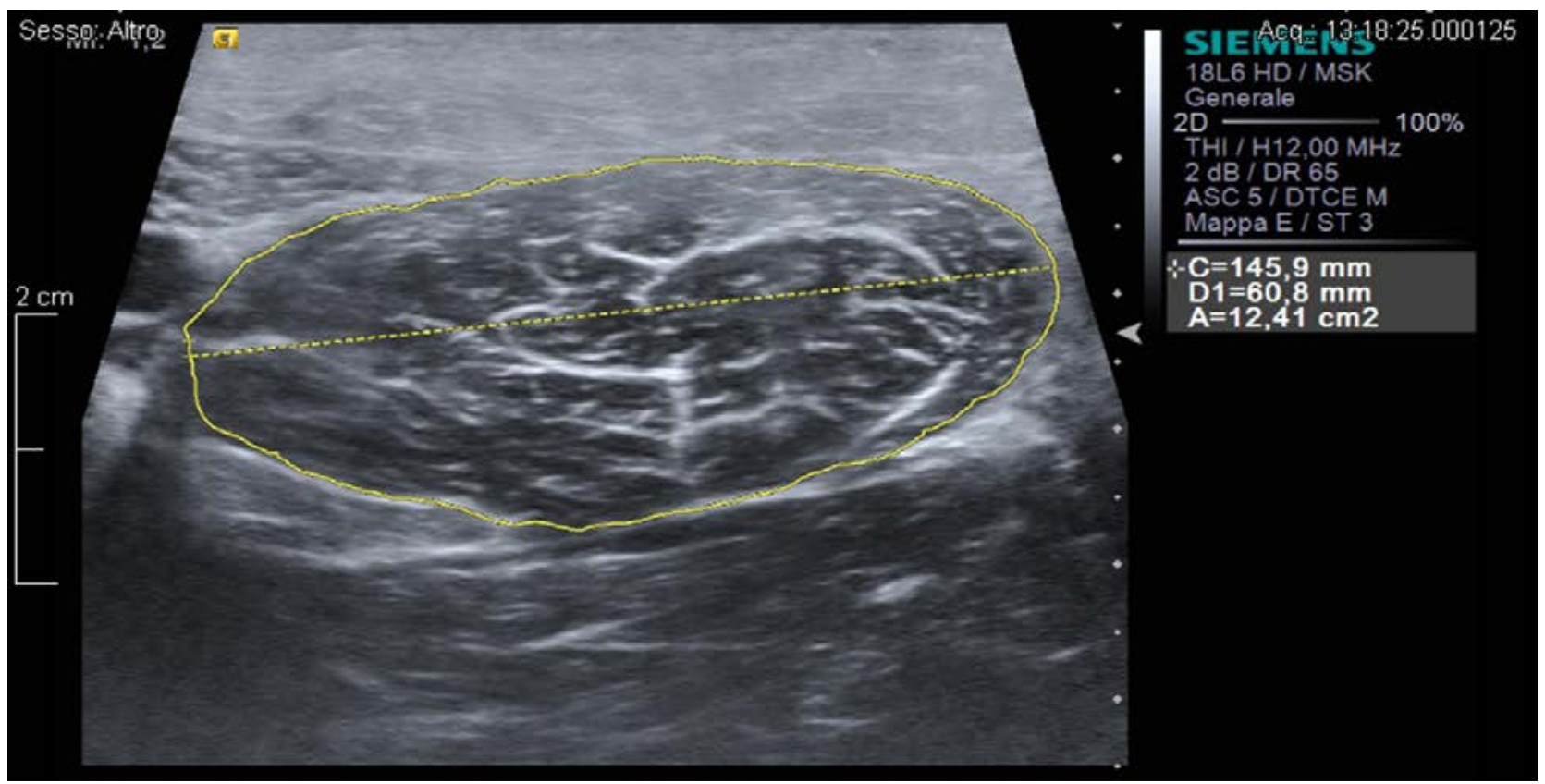

FIGURE 2: CSA

ultrasound measurements measured by the same operator and the other measurements obtained from 4 different specialists: a physiatrist, a radiologist, a general internist, and a family practitioner.

Intra-observer (ICC 0.92-0.97), interobserver (ICC 0.78-0.92) reproducibility was good to excellent for each measurement (Table 1). There were no statistical differences between measurements obtained from the same operator and different operators.

We confirmed the measurement accuracy, after having performed the same measurement three times.

\section{DISCUSSION}

Ultrasound is accurate, reproducible and fast; it offers a regional and easy evaluation. It should be taken into consideration when routine clinical examinations are performed or to evaluate patients with specific diseases ${ }^{2}$. The measurement of muscle size is essential to assess the effects of training, disuse, and ageing ${ }^{3}$. Different radiological techniques are used to examine muscle characteristics. The 'gold standard' for CSA measurements is magnetic resonance imaging (MRI). However, MRI is costly and 


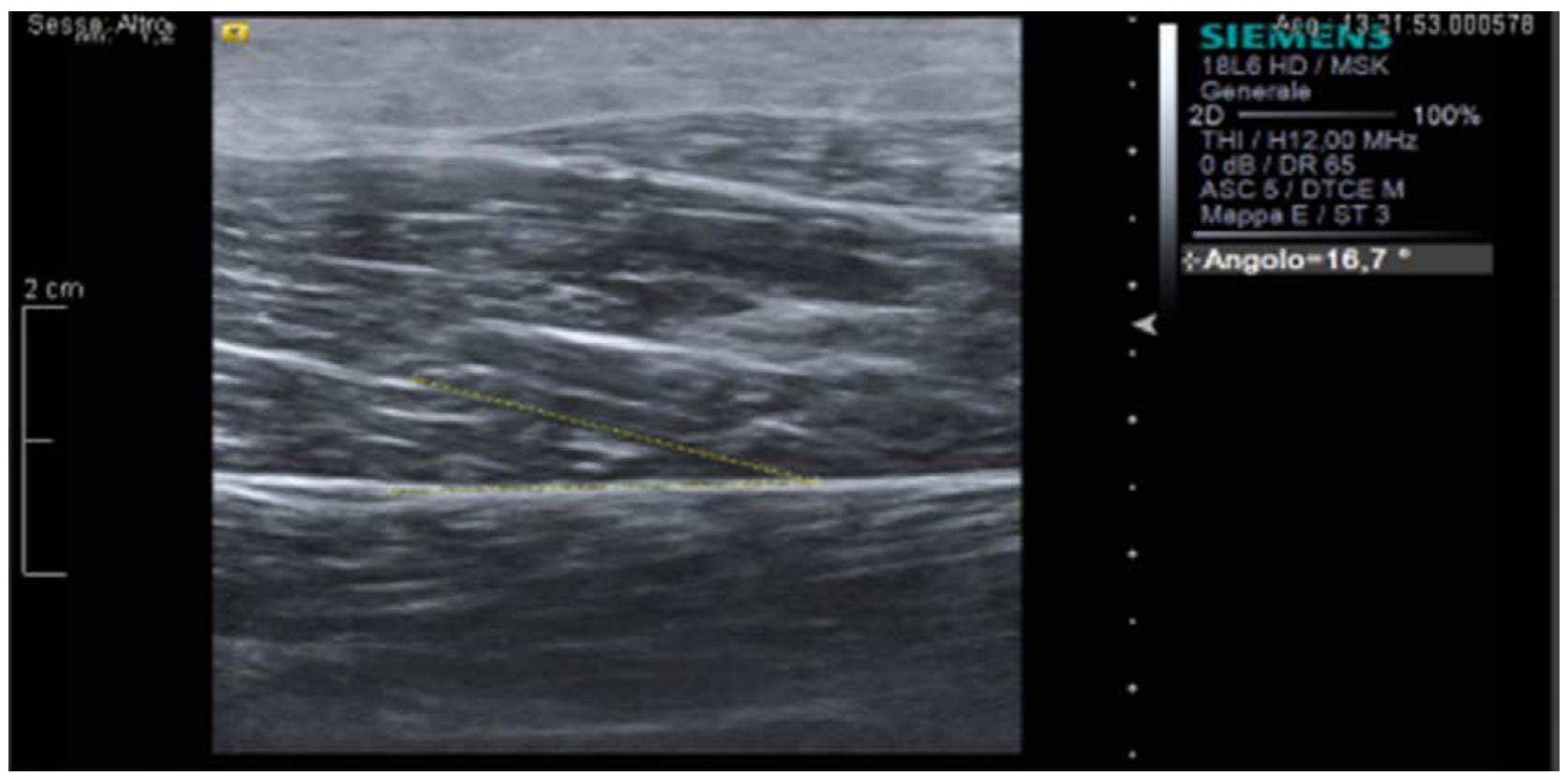

FIGURE 3: MUSCLE FIBER PENNATION ANGLE

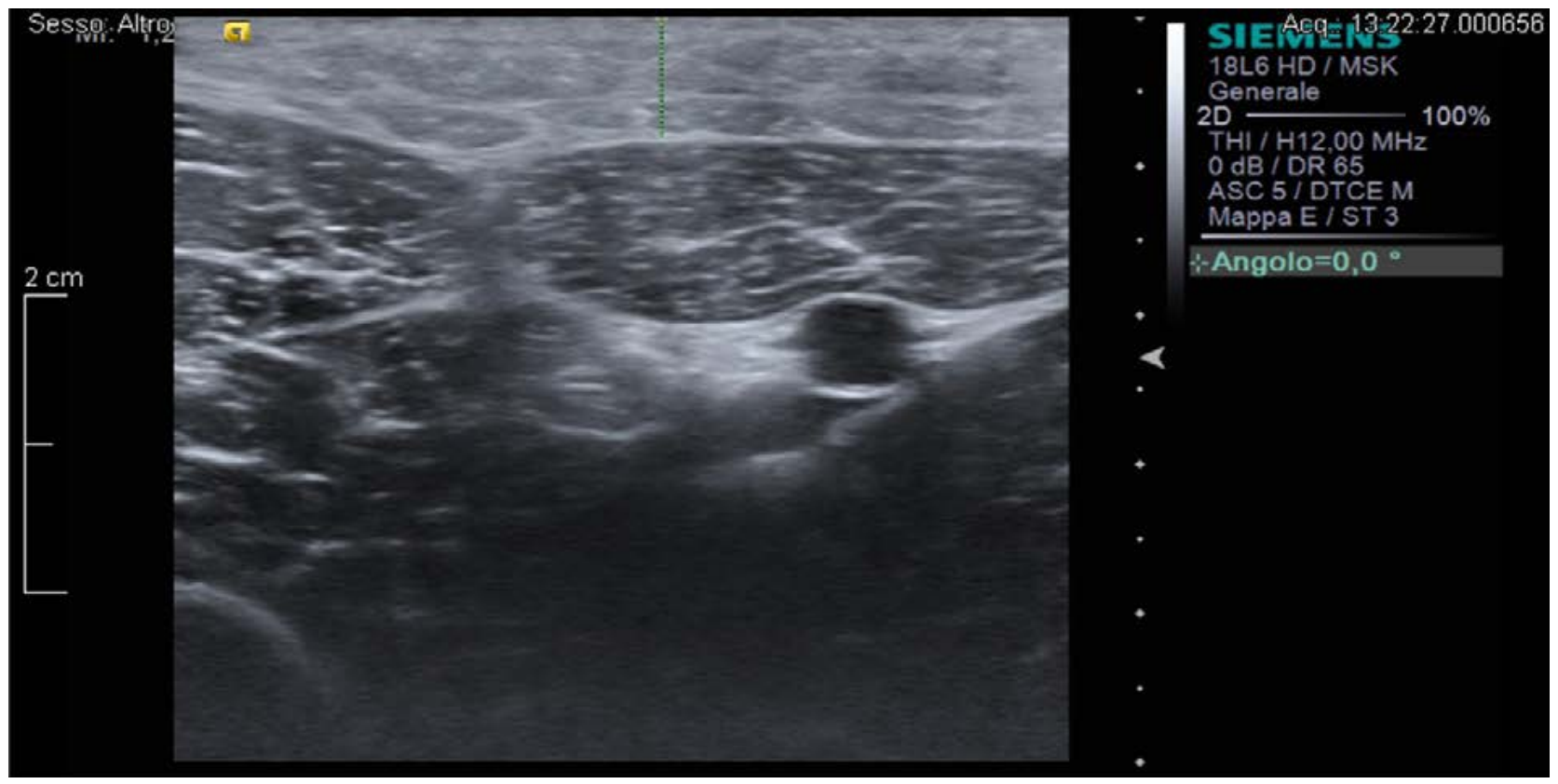

FIGURE 4: SUBCUTANEOUS FAT THICKNESS

often inaccessible ${ }^{4}$. So, US is the method of choice to examine muscle characteristics. Musculoskeletal ultrasound imaging is used to investigate muscle structure regarding architecture (MT, fascicle length, $\theta p$ ) and texture. The gray-scale analysis is commonly used to distinguish between normal and pathologic muscles; it depends on the image acquisition system and its setting $\mathrm{s}^{5-13}$. Hypertrophy of the pennate muscles is associated with a proportional increase in pennation angle but not necessarily in fascicle length, and with training-induced changes in muscle size ${ }^{5}$. Many pieces of research evaluated the capacity of ul- trasound to measure the parameters of the muscles in healthy and unhealthy people. Also, age or gender could influence muscle architecture. The fascicle, muscle, and tendon lengthen proportionally during the maturation; thus the muscle-tendon stiffness and excursion range are likely to be similar in children and adults, but the relatively higher increase in CSA than fascicle length indicates that adult muscles are better designed for force production than muscles of children $^{10,12}$. Another study described a lower ECHO, bigger muscle size in men, who were faster and more potent than women ${ }^{7}$. A study suggested that there 
TABLE 1: INTRA-OBSERVER AND INTER-OBSERVER REPRODUCIBILITY

\begin{tabular}{|c|c|c|c|c|}
\hline $\begin{array}{l}\text { Measure- } \\
\text { ments }\end{array}$ & $\begin{array}{l}\text { Sample } \\
\text { size } n .\end{array}$ & Average & $\begin{array}{l}\text { Inter-observ- } \\
\text { er }(95 \% \mathrm{Cl})\end{array}$ & $\begin{array}{l}\text { Intra-observer } \\
(95 \% \mathrm{Cl})\end{array}$ \\
\hline MT & \multirow{4}{*}{21} & 27.2 & 0.97 & 0.92 \\
\hline CSA & & 12.9 & 0.92 & 0.78 \\
\hline$\theta p$ & & 16.9 & 0.95 & 0.86 \\
\hline $\begin{array}{l}\text { Subcu- } \\
\text { taneous } \\
\text { adiposity }\end{array}$ & & 4.5 & 0.97 & 0.89 \\
\hline
\end{tabular}

MT thickness at rest, CSA cross-sectional area, $\theta p$ muscle fiber pennation angle

was no statistically significant difference between ultrasound estimation of muscle volume in vivo and in cadavers and there was no statistical difference between operators who determined muscle volume in vivo ${ }^{6}$. Other researchers showed that US is a valid and reliable method to measure quadriceps muscle size. They correlated computed tomography (CT) and $\mathrm{US}^{9}$ or magnetic resonance imaging (MRI) and US'. Our and other studies showed a positive correlation between the MT and the $\theta p^{4}$.

Compared to other researchers, our sample was more homogeneous for relevant sociodemographic variables, general clinical features, and clinical characteristics. Our purpose was to obtain more objective parameters than before and to show our protocol of muscle ultrasound. Few studies paid attention to a specific diagnostic sequence ${ }^{2,10}$. So, the physiatrist could clinically monitor the subjects and their structure of muscle fiber, even if the ultrasound were performed by other health care practitioners. Our ultrasound protocol permitted physiatrists to be more accurate in the evaluation of clinical pictures and in the follow-up. We aimed to standardize the US imaging, to reduce confusion in imaging interpretations, to provide a common language among clinicians regarding the significance of the findings and management recommendations, to facilitate outcomes monitoring and to design an individual exercise programme.

\section{CONCLUSIONS}

We observed accuracy, precision, and repeatability of ultrasonography in the evaluation of muscle architecture. Repeated measurements showed that the measurement techniques of this study were highly reproducible, so we concluded that US was a valid method for the evaluation of muscle structure. Simple, reproducible, non-invasive ultrasound measurements of muscle structure easily demonstrated differences in muscle morphology. So, we can evaluate and monitor changes in muscle architecture, due to training in sportsman or due to disease.

The discriminative ability of sonographers attests their levels of training, but expert operators can obtain objective data of the muscles structure. Even if sonographers are competent, guidelines and landmarks are necessary to obtain a better performance of the US study. With a protocol and with objective and repeatable measurements, sonographers from different backgrounds could obtain an objective measurement of ultrasound images with little differences and low variability in results, thanks to the upgrading of diagnostic ultrasound imaging and their clinical skills.

\section{RESUMO}

OBJETIVO: Nós utilizamos ultrassonografia de alta resolução em tempo real para investigar os parâmetros da arquitetura muscular do vasto lateral em voluntários saudáveis.

PROPÓSITO: Nós determinamos da reproduzibilidade e validade da ultrassonografia e o papel do ultrassonografista na avaliação da arquitetura muscular. Nós propomos os parâmetros clínicos mais apropriados para uma medição objetiva e um protocolo de ultrassonografia para arquitetura muscular.

MÉTODOS: Nós conduzimos um estudo intra-observador e inter-observador. Investigamos 21 voluntários saudáveis do sexo masculino. Os participantes foram avaliados de forma independente por quatro operadores diferentes usando ultrassonografia de alta-resolução em tempo real. Para avaliar a reprodutibilidade dos exames de ultrassonografia, quatro operadores repetiram as medições usando o mesmo equipamento de ultrassonografia. A espessura e o volume do músculo, o ângulo de penação da fibra muscular, adiposidade subcutânea do músculo vasto lateral foram medidos.

RESULTADOS: A reprodutibilidade intra-observador (ICC 0,92-0,97) e inter-observador (ICC 0,78-0,92) foi boa a excelente para todas as medições.

CONCLUSÃo: Medições de ultrassonografia simples, reprodutíveis e não-invasivas da estrutura muscular demostraram facilmente as diferenças na morfologia muscular. Seguindo um protocolo e com medições objetivas e reproduzíveis, ultrassonografistas com dif- 
erentes formações e experiências podem conseguir uma medição objetiva de imagens de ultrassonografia com poucas diferenças e pouca variação nos resultados graças à melhoria da qualidade nos exames de diagnóstico por imagem de ultrassonografia e das habilidades clínicas.

PALAVRAS-CHAVE: Ultrasonografia. Músculo quadríceps. Fibras musculares esqueléticas.

\section{REFERENCES}

1. Ahtiainen JP, Hoffren M, Hulmi JJ, Pietikäinen M, Mero AA, Avela J, et al. Panoramic ultrasonography is a valid method to measure changes in skeletal muscle cross-sectional area. Eur J Appl Physiol. 2010;108(2):273-9.

2. Bazzocchi A, Filonzi G, Ponti F, Sassi C, Salizzoni E, Battista G, et al. Accuracy, reproducibility and repeatability of ultrasonography in the assessment of abdominal adiposity. Acad Radiol. 2011;18(9):1133-43.

3. Delcker A, Walker F, Caress J, Hunt C, Tegeler C. In vitro measurement of muscle volume with 3-dimensional ultrasound. Eur | Ultrasound. 1999;9(2):185-90.

4. Ema R, Wakahara T, Mogi Y, Miyamoto N, Komatsu T, Kanehisa H, et al. In vivo measurement of human rectus femoris architecture by ultrasonography: validity and applicability. Clin Physiol Funct Imaging. 2013;33(4):26773.

5. Ema R, Wakahara T, Miyamoto N, Kanehisa H, Kawakami Y. Inhomogeneous architectural changes of the quadriceps femoris induced by resistance training. Eur J Appl Physiol. 2013;113(11):2691-703.

6. Infantolino BW, Gales DJ, Winter SL, Challis JH. The validity of ultrasound estimation of muscle volumes. J Appl Biomech. 2007;23(3):213-7.

7. Mangine GT, Fukuda DH, LaMonica MB, Gonzalez AM, Wells AJ,
Townsend JR, et al. Influence of gender and muscle architecture asymmetry on jump and sprint performance. J Sports Sci Med. 2014;13(4):904-11.

8. Molinari F, Caresio C, Acharya UR, Mookiah MR, Minetto MA. Advances in quantitative muscle ultrasonography using texture analysis of ultrasound images. Ultrasound Med Biol. 2015;41(9):2520-32.

9. Noorkoiv M, Nosaka K, Blazevich A). Assessment of quadriceps muscle cross-sectional area by ultrasound extended-field-of-view imaging. Eur J Appl Physiol. 2010;109(4):631-9.

10. O'Brien TD, Reeves ND, Baltzopoulos V, Jones DA, Maganaris CN. Muscle-tendon structure and dimensions in adults and children. I Anat. 2010;216(5):631-42

11. Pasta G, Nanni G, Molini L, Bianchi S. Sonography of the quadriceps muscle: Examination technique, normal anatomy, and traumatic lesions. J UItrasound. 2010;13(2):76-84.

12. Pillen $S$, van Keimpema M, Nievelstein RA, Verrips A, van Kruijsbergen-Raijmann W, Zwarts MI. Skeletal muscle ultrasonography: visual versus quantitative evaluation. Ultrasound Med Biol. 2006;32(9):1315-21.

13. Reeves ND, Maganaris CN, Narici MV. Ultrasonographic assessment of human skeletal muscle size. Eur J Appl Physiol. 2004;91(1):116-8. 